\title{
The Role of Hip Abductor Strength in Identifying Older Persons at Risk of Falls: A Diagnostic Accuracy Study
}

This article was published in the following Dove Press journal: Clinical Interventions in Aging

\author{
Simone Chantal Gafner (D) ${ }^{1,2}$ \\ Caroline Henrice Germaine \\ Bastiaenen $\mathbb{D D}^{2}$ \\ Serge Ferrari ${ }^{3}$ \\ Gabriel Gold ${ }^{4}$ \\ Andrea Trombetti ${ }^{5}$ \\ Philippe Terrier (iD ${ }^{6,7}$ \\ Roger Hilfiker ${ }^{8}{ }^{8}$ \\ Lara Allet $\mathbb{D}^{1,8,9}$
}

'Geneva School of Health Sciences, HESSO University of Applied Sciences and Arts Western Switzerland, Geneva, Switzerland; ${ }^{2}$ Department of Epidemiology, Research Line Functioning and Rehabilitation, CAPHRI, Maastricht University, Maastricht, the Netherlands; ${ }^{3}$ Department of Internal Medicine Specialties, University Hospitals and University of Geneva, Geneva,

Switzerland; ${ }^{4}$ Department of Internal Medicine, Rehabilitation and Geriatrics, University Hospitals and University of Geneva, Geneva, Switzerland; ${ }^{5}$ Division of Bone Diseases, Department of Medicine, University Hospitals and University of Geneva, Geneva, Switzerland; ${ }^{6}$ School of Health Sciences, ARC Santé, HES-SO University of Applied Sciences and Arts Western Switzerland, Neuchâtel, Switzerland; ${ }^{7}$ Department of Thoracic Surgery, University Hospitals and University of Geneva, Geneva, Switzerland; ${ }^{8}$ School of Health Sciences, HES-SO ValaisWallis, University of Applied Sciences and Arts Western Switzerland, Valais, Switzerland; ${ }^{9}$ Department of Community Medicine, University Hospitals and University of Geneva, Geneva, Switzerland

Correspondence: Simone Chantal Gafner Rue des Caroubiers 25, CH-I227

Carouge, Geneva, Switzerland

Tel +4I 223883470

Fax +4I 223883424

Email simone.gafner@hesge.ch
Background/Objectives: Early detection of fall risk in persons older than 65 is of clinical relevance, but the diagnostic accuracy of currently used functional tests (eg short physical performance battery [SPPB] and timed up and go test [TUG]) to assess older persons' fall risks remains moderate. Recent literature highlights the importance of strong hip abductors to prevent falls. We thus aimed to assess the diagnostic accuracy of hip abductor strength measures to assess older persons' fall risks.

Methods: Hip abductor maximum voluntary isometric strength (ABD MVIS), rate of force generation (ABD RFG), and the SPPB and TUG functional fall risk assessments were assessed in 60 persons aged over 65 years $(82.0 \pm 6.1$ years). The diagnostic accuracy (area under the curve [AUC], sensitivity [sens], specificity [spec], positive predictive value [PPV], negative predictive value [NPV], and positive and negative likelihood ratios [LR ${ }^{+}$, $\mathrm{LR}^{-}$]) was evaluated at a clinically important $90 \%$ sensitivity level. Cut-off values for clinical use were calculated.

Results: In our population, hip ABD MVIS (AUC 0.8, sens 90.6\%, spec 57.1\%, PPV $70.7 \%$, NPV 84.2\%, LR+ 2.1, LR- 0.2, and cut-off value $\leq 1.1 \mathrm{~N} / \mathrm{kg}$ ) and hip ABD RFG (AUC 0.8, sens 90.6\%, spec 46.4\%, PPV 65.9\%, NPV 81.3\%, LR+ 1.7, LR- 0.2, and cut-off $\leq 8.47 \mathrm{~N} / \mathrm{kg} / \mathrm{s}$ ) show diagnostic accuracy comparable to other fall risk assessments (SPPB and TUG) and a high net sensitivity when used in a test battery.

Conclusion: Hip ABD MVIS or RFG shows good diagnostic accuracy to differentiate between older fallers and nonfallers compared to the chosen external criterion history of falls. The high net sensitivity when hip ABD MVIS or RFG is combined with currently used fall risk assessments shows promise in contributing value to a test battery and should be investigated further in longitudinal studies.

Keywords: measurement study, muscle strength, hip, functional performance, accidental falls, aged

\section{Introduction}

The World Health Organization (WHO) reports a yearly fall rate of $28 \%$ to $35 \%$ in persons older than $65 .{ }^{1}$ For persons living in long-term care institutions, percentages are even higher and lay between $30 \%$ and $50 \%$.

Various functional tests are currently used to assess older persons' fall risks (eg timed up and go test [TUG] and short physical performance battery [SPPB]). However, the diagnostic accuracy (eg sensitivity and specificity) of these functional tests remains moderate. ${ }^{2,3}$ In addition, poor performance in a functional test indicates a fall risk but requires further tests to identify the underlying causes. It is thus 
of utmost importance to develop and use valid diagnostic fall risk assessment tools that can be used in everyday clinical practice and that indicate parameters that need to be targeted.

A combination of various factors often leads to a fall incident (eg muscle weakness, gait and balance problems, poor footwear, or poor lighting), ${ }^{4}$ which can cause serious consequences such as fractures, loss of independence, ${ }^{5}$ and increased mortality. ${ }^{6}$ Muscle strength has already been shown to be important in preventing falls. ${ }^{4}$ Recent literature further underlines the significance of hip abductor muscle strength to maintain mediolateral balance control, ${ }^{7-9}$ which is essential to avoid lateral and posterolateral falls. ${ }^{10}$ This is of clinical relevance because posterolateral falls have high hip injury potential and lead to fractures. ${ }^{11-13}$ In addition, it was shown that hip abductor muscle contractions at the moment of impact after a fall could substantially reduce stress at the femoral neck and likewise the risk of a femoral fracture. ${ }^{14}$ Therefore, hip abductor strength could be a promising contributing factor for the assessment of fall risk and establishment of cut-off values, and diagnostic accuracy might improve the clinical decision-making process regarding individuals' fall risks.

Our previous work confirmed the importance of hip abductor muscle strength and showed that the strength of the hip abductor muscle groups can, among all hip muscle groups (flexors, extensors, internal and external rotators and adductors), best distinguish between older fallers and nonfallers. $^{15}$

Therefore, the current study first aimed to investigate diagnostic accuracy (area under the curve [AUC], sensitivity [sens], specificity [spec], positive predictive value [PPV], negative predictive value [NPV], and positive and negative likelihood ratio [LR+, LR-]) of hip abductor strength (ABD maximum voluntary isometric strength [MVIS] and rate of force generation [RFG]) to distinguish between older fallers and nonfallers compared to a history of falling as the predefined reference standard. The second goal was to identify clinically relevant hip abductor strength (MVIS and RFG) cut-off values based on diagnostic accuracy outcomes to distinguish between older fallers and nonfallers evaluated by fall history as the same reference standard. The third aim was to compare the diagnostic accuracy of hip abductor strength with the diagnostic accuracy of currently used fall risk assessments (TUG and SPPB) in our population, as well as with published articles. The final goal was to calculate the net sensitivity and specificity of our population for parallel testing of ABD MVIS or ABD RFG with the mentioned currently used TUG and SPPB fall risk assessments.

We tested three hypotheses. First, hip abductor strength has a good diagnostic accuracy $(\geq 0.9)$ for clinical use to distinguish between older fallers and nonfallers. Second, the diagnostic accuracy of hip abductor strength shows values comparable to the diagnostic accuracy of currently used fall risk assessments (TUG and SPPB). Third, hip abductor strength (ABD MVIS and RFG), as a not yet systematically assessed parameter in the construct of fall risk, shows high accuracy in recognizing fallers in parallel testing with TUG and SPPB.

\section{Methods}

We performed a validity study to evaluate the diagnostic accuracy of hip ABD MVIS and ABD RFG for the fall risk evaluation of persons' older than 65. The Standards for Reporting of Diagnostic Studies (STARD) ${ }^{16}$ were followed (Figure 1 shows the STARD flow chart to report participants' flow through the study). Participants were simultaneously recruited from the Geriatric Department of the University Hospitals of Geneva and from an ambulatory setting. They were included when they were $\geq 65$ years, had a body mass index (BMI) between 17 and 35 and were able to walk household distances. We excluded participants in case of a positive history or evidence of any significant central nervous system dysfunction, neuromuscular disorders except a distal symmetric peripheral neuropathy, evidence of vestibular dysfunction, moderate or severe dementia (Minimal Mental State Exam $(\mathrm{MMSE})<18$ ), a fracture of the lower limb and/or joint replacement within the previous year and any lower limb or back pain that adversely affects the strength tests. ${ }^{15}$

This study is an extended evaluation and a next step to the results we presented in our previous article in which, as a first step, we evaluated which of the hip muscle groups is the most important to differentiate between older fallers and nonfallers. ${ }^{15}$ In the current study, we examine the diagnostic accuracy of hip abductor muscle strength to decide whether this parameter should be integrated into a test battery to assess older persons' fall risks. The diagnostic accuracy of a test is expressed by the area under the curve [AUC], sensitivity [sens], specificity [spec], positive predictive value [PPV], negative predictive value $[\mathrm{NPV}]$, and positive and negative likelihood ratio [LR+, LR-].

The area under the receiver operating curves is the AUC, the higher the value of the AUC the better a test discriminates between two groups. ${ }^{17}$ Sensitivity and specificity reflect the 


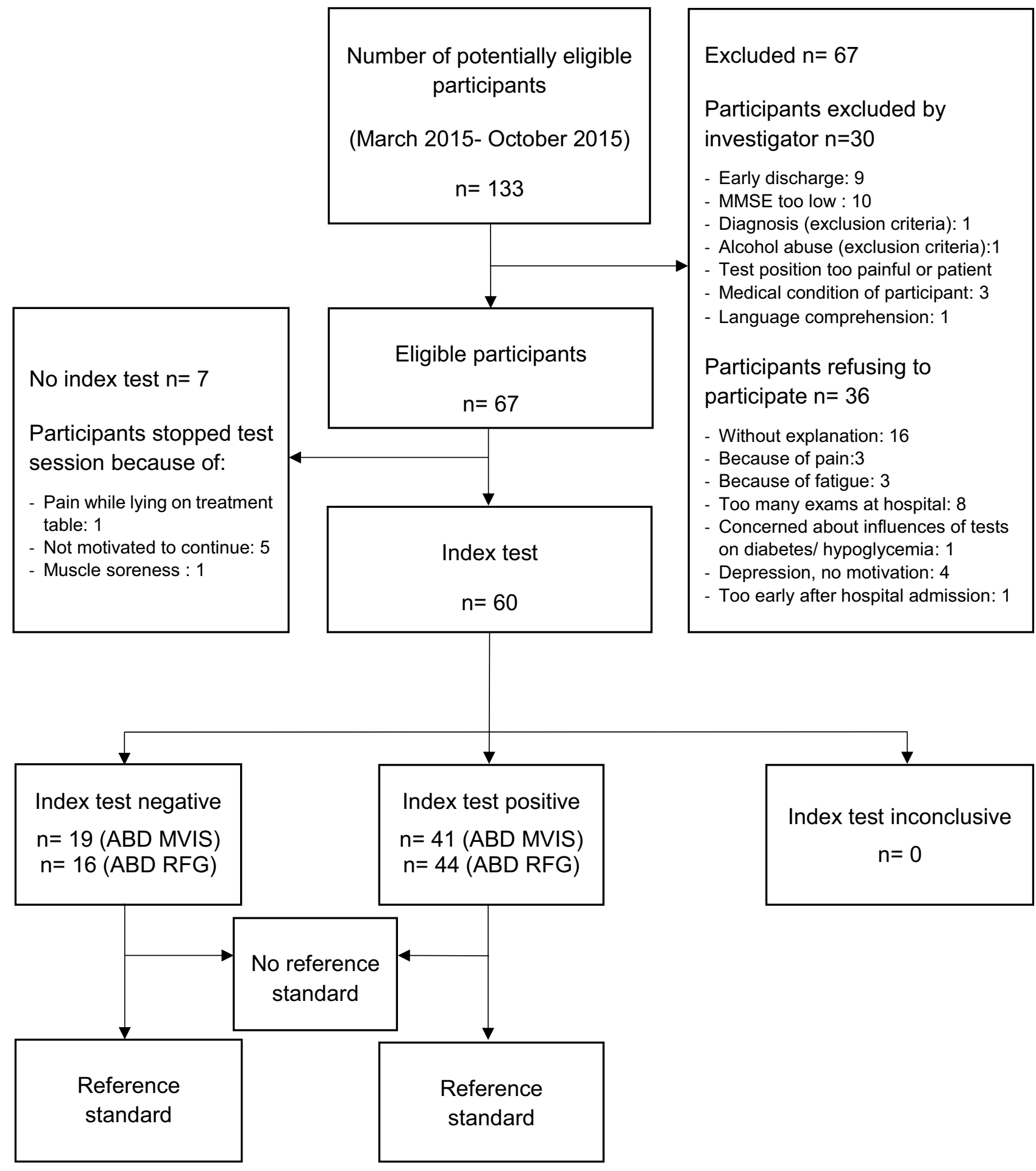

Figure I STARD diagram of participants' flow through the study.

intrinsic quality of a test and show the ability of a measurement instrument to detect true positives or true negatives, respectively. ${ }^{18}$ The likelihood ratio is calculated based on sensitivity and specificity. ${ }^{18}$ The positive likelihood ratio is a value for how much more likely a positive test result is in people with the disease than in people without the disease. ${ }^{18}$ How much less likely a negative test result is in people with the disease than in people without the disease is expressed by the negative likelihood ratio. ${ }^{18}$ The larger the value above one (for $\mathrm{LR}+$ ), respectively the smaller the value 
below one (for LR-), the more valuable is the test result. ${ }^{18}$ Positive and negative predictive values are the probability of the disease in a patient with a positive test result or the probability of not having the disease when the test result is negative, respectively. ${ }^{17}$

The study was conducted according to the Declaration of Helsinki and the local ethics committee (commission cantonal d'éthique de la recherche Geneva, CCER) approved the study protocol (14-235). Participants received verbal and written information about the study content, and they signed informed consent forms prior to the first tests.

\section{Procedure}

All of the included patients' demographic data (eg age, sex, and BMI) were extracted from the clinical database. The reference standard fall history was collected by verbal questioning.

Thereafter, trained physical therapists (blinded to the participants' fall histories) assessed the Falls Efficacy Scale International (FES-I), ${ }^{19}$ Mini Mental State Examination (MMSE), ${ }^{20}$ the $\mathrm{SPPB}^{21}$ and $\mathrm{TUG}^{22}$ functional fall risk assessments, as well as participants' hip abductor strength (MVIS and RFG) following our study protocol's procedure.

\section{Index Measure: Hip Abductor Strength}

Hip abductor strength was measured in Newtons (N) using an analog dynamometer (Sensix, Poitiers, France) with a range from 0 to $667 \mathrm{~N}$ and a precision of $0.002 \mathrm{~N}^{23}$ The Delsys System (Trigno sensor, Delsys, Inc., Boston, MA) coupled with the calibrated dynamometer digitalized the output (3.3 V) with a sampling rate of $1926 \mathrm{~Hz}$ and a 16-bit resolution. ${ }^{23}$

For hip abductor strength (ABD) tests, participants lay on their sides and performed hip ABD with the upper leg in a $10^{\circ}$ abducted position. ${ }^{23}$ The lower leg was at $45^{\circ}$ of knee and hip flexion for stabilization. Participants were asked to keep the knee of their tested leg extended with the hip in a neutral or slightly extended position. ${ }^{23}$ For the test, the examiner manually supported the leg's starting position $1 \mathrm{~cm}$ from the dynamometer that was positioned $5 \mathrm{~cm}$ proximal to the malleolus externus. ${ }^{23,24}$

To measure MVIS and RFG, participants were asked to push as hard and fast as possible against the dynamometer, ${ }^{25}$ hold the pressure for $3 \mathrm{~s}$, and relax. ${ }^{26}$ To avoid bias through dynamometer destabilization or the testing person's strength, the dynamometer was fixed to a metallic frame at the appropriate height for the described $10^{\circ}$ abduction starting position.
Participants repeated the test 3 times per leg with a break of $1 \mathrm{~min}$ between trials. In accordance with our pilot tests, the mean of the 6 trials was retained for further analyses. Details of the measurement procedure and information about the feasibility and reliability of the test are described elsewhere. ${ }^{15,23}$

\section{Functional Fall Risk Assessments}

Short physical performance battery: The SPPB estimates the function of the lower limbs. It is divided into 3 parts: the evaluation of standing balance, walking speed, and lower limb strength with a 5 sit to stand test. ${ }^{21,27}$ The final score ranges from 0 to 12 points and is calculated by summarizing the scores of the 3 parts.

Timed up and go test: For the TUG, participants were asked to get up from a chair with armrests, walk $3 \mathrm{~m}$ at usual gait speed, perform a turn, and return to the chair to sit down again. Participants were allowed a test trial. Thereafter, the time needed to complete the task once was recorded in seconds. ${ }^{28}$

\section{Reference Standard: Fall History}

To classify our study participants into fallers and nonfallers, a history of falls during the previous 12 months was chosen as a reference standard. A faller was defined as a participant who reported one or more falls within the previous year. ${ }^{29}$ Participants who did not report a fall were classified as nonfallers. ${ }^{29}$ Participants were informed that a fall was defined as an event resulting in a person inadvertently coming to rest on the ground, floor, or other lower level. ${ }^{1}$ We did not include falls resulting from unavoidable environmental hazards, such as a chair collapsing. ${ }^{22}$

\section{Sample Size}

We expected to find high sensitivity levels comparable with currently used fall risk assessment tools (sensitivity between 0.6 and 0.9 ). To test the null hypothesis, $\mathrm{H}_{0}$ : sensitivity $=0.6$ $\left(\mathrm{H}_{1}\right.$ : sensitivity $\left.\neq 0.6\right)$ with an expected sensitivity of 0.9 , a minimum sample of $\mathrm{n}=19$ persons with the disease (fallers) and a total sample of $n=48$ is appropriate to achieve a $<5 \%$ significance level and $80 \%$ power. $^{30}$ To compensate for an expected $20 \%$ dropout rate, we aimed to include 60 participants.

\section{Statistics}

Statistical analyses were performed with Stata version 14.1 (College Station, Texas 77845, USA). 


\section{Data Processing}

After downloading raw data to a computer, Matlab (Mathworks, Natick, MA, USA) was used to process the force data. A low-pass filter (75 ms moving average) suppressed high-frequency noise. The MVIS was defined as the highest force generated by the subject within $3 \mathrm{~s}$ from the beginning of the test. The RFG was evaluated within a 50 ms time window after $10 \%$ of the MVIS was reached. ${ }^{23}$ MVIS and RFG were normalized to body mass. ${ }^{15}$

\section{Main Analyses}

The characteristics of the study sample were described with mean and standard deviations. Area under the curves were calculated from logistic regressions with their corresponding 95\% confidence intervals (95\% CI).

To achieve a high probability to detect as many persons at risk of falls as possible, high test sensitivity is important (ie a test's ability to detect affected persons). A way to increase the "certainty" of detecting at-risk persons is to perform two different tests simultaneously (parallel testing), which leads to a gain in sensitivity (net sensitivity).

To obtain a high number of true positives (and consequently a lower number of false negatives), we decided to evaluate the diagnostic accuracy of our index measure closest above the clinically important $90 \%$ sensitivity level for discrimination. Therefore, sensitivity and specificity (with corresponding 95\% confidence intervals) were calculated based on cut-offs closest to the value that yielded in a sensitivity of $\geq 0.9$. Positive and negative predictive values, as well as likelihood ratios for positive $(\mathrm{LR}+)$ and negative (LR-) tests, were calculated (with corresponding 95\% confidence intervals) accordingly.

For the calculations of the net sensitivity and net specificity, we additionally present the calculations with the Youden Index, Youden's J ( $\mathrm{J}=$ Sensitivity + Specificity $-1)$ with the corresponding cut-offs. We further analyzed and presented indices for discrimination and calibration of our logistic regression models.

Finally, we also calculated calibration plots of the logistic regression model with the Hosmer-Lemeshow test, with a significance level (type-I error) of $5 \%$. We plotted our observed values for falls against the predicted probabilities of falls for groups defined by ranges of $20 \%$ for the predicted risk, as well as their slopes and intercepts. ${ }^{31}$

\section{Results}

We evaluated the diagnostic accuracy of hip abductor MVIS and RFG in 60 participants (mean age 82 years,
SD 6.61 years, 28 older nonfallers and 32 older fallers). The descriptive statistics for age, sex, BMI, FES-I, MMSE, SPPB, and TUG are presented in Table 1.

The diagnostic accuracy (AUC, sens, spec, PPV, NPV, and LR+ and LR-) to discriminate between older fallers and nonfallers using hip abductor MVIS and RFG as well as the corresponding cut-off values of our sample are presented in Table 2.

The diagnostic accuracy to distinguish between older fallers and nonfallers of ABD MVIS, ABD RFG, TUG, and SPPB shows comparable values (values range between the following: sens $90.6-93.9 \%$, Spec $46.4-71.5 \%$, PPV 65 . 9-78.4\%, NPV 81.3-88.2\%, LR+ 1.7-3.2, LR- 0.1-0.2). However, hip ABD MVIS shows a slightly higher diagnostic accuracy (AUC 0.8 [95\% CI, 0.7-0.9], sens 90.6\% [75.098.0], spec 57.1\% [37.2-75.5], PPV 70.7\% [51.8-92.5], NPV 84.2\% [62.3-92.5], LR+ 2.1 [1.4-3.3], LR- 0.2 [0.10.5]) than hip ABD RFG (AUC 0.8 [95\% CI, 0.7-0.9], sens 90.6\% [75.0-98.0], spec 46.4\% [27.5-66.1], PPV 65.9\% [45.8-90.8], NPV 81.3\% [57.3-90.7], LR+ 1.7 [1.2-2.4], LR- 0.2 [0.1-0.6]) (Table 2). The cut-off values to distinguish between fallers and nonfallers are $\leq 1.1 \mathrm{~N} / \mathrm{kg}$ for ABD MVIS and $\leq 8.5 \mathrm{~N} / \mathrm{kg} / \mathrm{s}$ for ABD RFG.

In Table 3, the cross-tabulation of the index tests (hip ABD MVIS or RFG) is presented against the results of the reference standard. This allows to identify the true positive, true negative, false positive and false-negative cases. Our ABD MVIS and RFG model, as well as SPPB and TUG, showed good calibration (small discrepancy between predicted probability of falls on the $\mathrm{x}$-axis and observed proportion of falls on the $\mathrm{y}$-axis, all $\mathrm{P}$ values $>$ 0.05 , Figure 2). This means that for example for the hip ABD MVIS values (Figure 2A) for the participants we

Table I Characteristics of our study participants

\begin{tabular}{|l|l|l|l|}
\hline Variable & $\begin{array}{l}\text { Total Group } \\
\text { Mean (SD) }\end{array}$ & $\begin{array}{l}\text { Fallers } \\
\text { Mean (SD) }\end{array}$ & $\begin{array}{l}\text { Nonfallers } \\
\text { Mean (SD) }\end{array}$ \\
\hline Sex (F/M) & $38 / 22$ & $21 / 11$ & $17 / 11$ \\
Age (years) & $81.2(6.6)$ & $83.3(6.2)$ & $80.4(6.8)$ \\
Weight $(\mathrm{kg})$ & $65.9(12.1)$ & $63.8(12.7)$ & $68.3(11.2)$ \\
BMI $\left(\mathrm{kg} / \mathrm{m}^{2}\right)$ & $24.3(3.4)$ & $24.3(3.9)$ & $24.3(2.9)$ \\
Hospitalized (\%) & 71.7 & 96.9 & 42.9 \\
MMSE & $26.0(3.5)$ & $24.3(3.6)$ & $27.8(2.1)$ \\
FES-I & $24.5(7.1)$ & $26.5(7.0)$ & $22.2(6.5)$ \\
SPPB & $8.2(3.1)$ & $6.3(2.3)$ & $10.3(2.4)$ \\
TUG (s) & $15.9(9.0)$ & $20.0(9.4)$ & $11.3(5.8)$ \\
\hline
\end{tabular}

Abbreviations: BMI, body mass index; MMSE, mini mental state examination; FES-I, falls efficacy scale international; SPPB, short physical performance battery; TUG, timed up and go test; s, seconds. 
Table 2 The diagnostic accuracy to discriminate between older fallers and nonfallers of hip abductor strength (MVIS and RFG) and the performance tests SPPB and TUG, as well as their corresponding cut-off values evaluated by the closest sensitivity value $>90 \%$

\begin{tabular}{|c|c|c|c|c|c|c|c|c|}
\hline Variable & $\begin{array}{l}\text { AUC } \\
(95 \% \mathrm{Cl})\end{array}$ & $\begin{array}{l}\text { Sens \% } \\
(95 \% \mathrm{Cl})\end{array}$ & $\begin{array}{l}\text { Spec \% } \\
(95 \% \mathrm{Cl})\end{array}$ & $\begin{array}{l}\text { PPV \% } \\
(95 \% \mathrm{Cl})\end{array}$ & $\begin{array}{l}\text { NPV \% } \\
(95 \% \mathrm{Cl})\end{array}$ & $\begin{array}{l}\text { LR+ } \\
(95 \% \mathrm{Cl})\end{array}$ & $\begin{array}{l}\text { LR- } \\
(95 \% \mathrm{Cl})\end{array}$ & Cut-off \\
\hline ABD MVIS (N/kg) & $0.8(0.7,0.9)$ & $90.6(75.0,98.0)$ & $57.1(37.2,75.5)$ & $70.7(51.8,92.5)$ & $84.2(62.3,92.5)$ & $2.1(1.4,3.3)$ & $0.2(0.1,0.5)$ & $\leq 1.1$ \\
\hline ABD RFG $(\mathrm{N} / \mathrm{kg} / \mathrm{s})$ & $0.8(0.7,0.9)$ & $90.6(75.0,98.0)$ & $46.4(27.5,66.1)$ & $65.9(45.8,90.8)$ & $81.3(57.3,90.7)$ & $1.7(1.2,2.4)$ & $0.2(0.1,0.6)$ & $\leq 8.5$ \\
\hline SPPB (//2) & $0.9(0.8,1.0)$ & $90.6(75.0,98.0)$ & $71.4(51.3,86.8)$ & $78.4(60.5,94.9)$ & $87.0(67.4,94.6)$ & $3.2(1.7,5.8)$ & $0.1(0.0,0.4)$ & $\leq 9.0$ \\
\hline TUG (sec) & $0.8(0.7,0.9)$ & $93.8(79.2,99.2)$ & $53.6(33.9,72.5)$ & $69.8(53.9,82.8)$ & $88.2(63.6,98.5)$ & $2.0(1.3,3.0)$ & $0.1(0.0,0.5)$ & $\geq 10.0$ \\
\hline
\end{tabular}

Abbreviations: AUC, area under the curve; Sens, sensitivity; Spec, specificity; PPV, positive predictive value; NPV, negative predictive value; LR+, positive likelihood ratio; LR-, negative likelihood ratio; $95 \% \mathrm{Cl}$; $95 \%$ confidence interval; ABD MVIS, hip abductor maximum voluntary isometric strength; ABD RFG, hip abductor rate of force generation; SPPB, short physical performance battery; TUG, timed up and go test; sec, seconds; N, Newton; s, seconds.

Table 3 Cross tabulation of the index measure (Left; ABD MVIS, Right; ABD RFG) against the reference standard history of falling

\begin{tabular}{|l|l|l|l|l|l|l|l|}
\hline \multirow{2}{*}{$\begin{array}{l}\text { Hip ABD MVIS } \\
\leq \text { I.I N/kg }\end{array}$} & \multicolumn{2}{|l|}{ Total } & \multirow{2}{*}{$\begin{array}{l}\text { Hip ABD RFG } \\
\leq \mathbf{8 . 4 7} \text { N/kg/s }\end{array}$} & \multicolumn{2}{l|}{ Fall History } \\
\cline { 2 - 5 } & Positive & Negative & & & & Positive & Negative \\
\hline Positive & 29 & 12 & 41 & Positive & 29 & 15 & 44 \\
Negative & 3 & 16 & 19 & Negative & 3 & 13 & 16 \\
Total & 32 & 28 & 60 & Total & 32 & 28 & 60 \\
\hline
\end{tabular}

Abbreviations: ABD MVIS, hip abductor maximum voluntary isometric strength; ABD RFG, hip abductor rate of force generation.

predicted about a $10 \%$ risk of falls (x-axis) we really observed a risk of falls of about $10 \%$ (y-axis). A perfect prediction lays on the $45^{\circ}$ line. The net sensitivities and specificities for the parallel testing of the currently used TUG and SPPB fall risk assessment tools with hip ABD MVIS and RFG of our population are presented in Table 4 (once for sensitivity $\geq 90 \%$ and once for the sensitivity evaluated with the Youden Index). Table 4 shows that performing 2 tests simultaneously (ABD MVIS or ABD RFG combined with either TUG or SPPB) leads to a very high net sensitivity (between 96.5 and 99.4) in our study sample.

\section{Discussion}

We hypothesized the following; first, for clinical use, hip abductor strength has good diagnostic accuracy to distinguish between older fallers and nonfallers. Second, the diagnostic accuracy of hip abductor strength is comparable with the diagnostic accuracy of currently used fall risk assessments (TUG and SPPB). Third, hip abductor strength (ABD MVIS and RFG) shows good values by which to recognize fallers in parallel testing with TUG and/or SPPB.

Our results support our hypotheses. In our population, hip ABD strength shows good diagnostic accuracy to distinguish between older fallers and nonfallers, comparable to values of other functional fall risk and/or mobility assessment tools. Hip ABD MVIS (AUC 0.8 [95\% CI, 0.7-0.9], cut-off value $\leq 1.1 \mathrm{~N} / \mathrm{kg}$ ) shows a slightly higher diagnostic accuracy than hip ABD RFG (AUC 0.8 [95\% CI, 0.7-0.9], cut-off $\leq 8.5 \mathrm{~N} / \mathrm{kg} / \mathrm{s}$ ) (Table 2). ABD MVIS's slightly better diagnostic accuracy compared to ABD RFG seems rather unexpected as clinically one can assume that RFG is more important in fall prevention since a fast recovery step after tripping is necessary to regain balance and prevent falls. ${ }^{32}$ However, this might be because our participants' ABD MVIS and RFG were evaluated within the same trial. For older persons, our combined instructions to push as hard and as fast as possible to evaluate ABD MVIS and ABD RFG in the same trial was very complex. Therefore, for a clear differentiation of the 2 variables (MVIS and RFG), we recommend a separation of the trials to evaluate ABD MVIS and ABD RFG in future studies.

For clinical use, a quick and easy assessment with good diagnostic accuracy is essential. So far, various studies have assessed the diagnostic accuracy of the TUG or the SPPB to assess older persons' fall risks, 2 tests that are easily applicable in a relatively short timeframe. ${ }^{2,33}$ Within our population, the ABD MVIS, ABD RFG, TUG, and SPPB showed comparable diagnostic accuracy (Table 2). This might be surprising as the hip ABD MVIS and ABD 
A Observed vs. Predicted (HipABD MVIS)

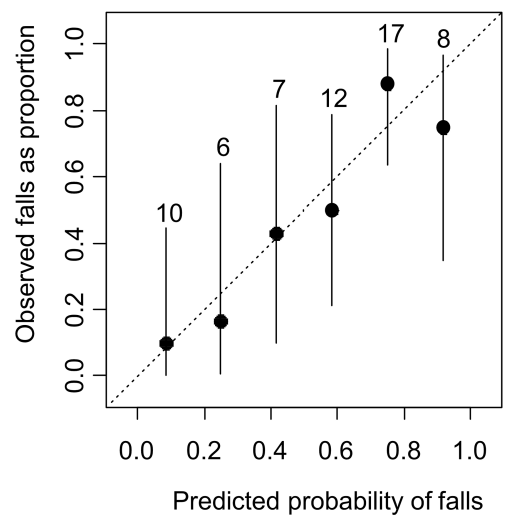

C Observed vs. Predicted (SPPB)

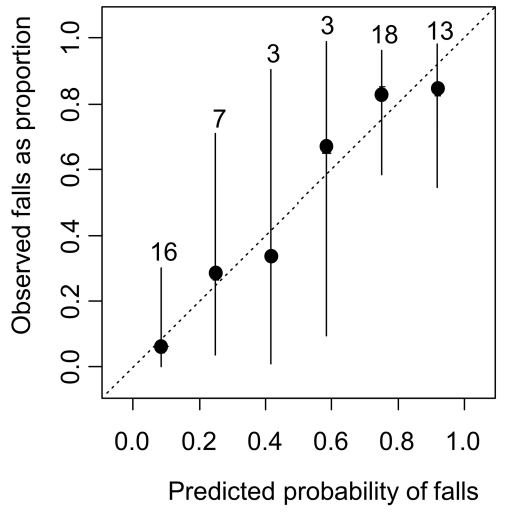

B Observed vs. Predicted (HipABD RFG)

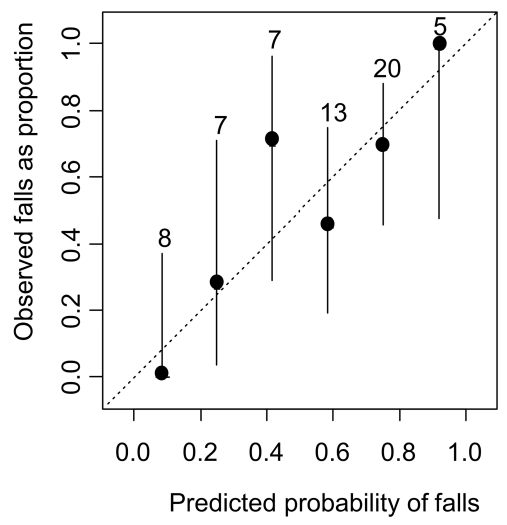

D Observed vs. Predicted (TUG)

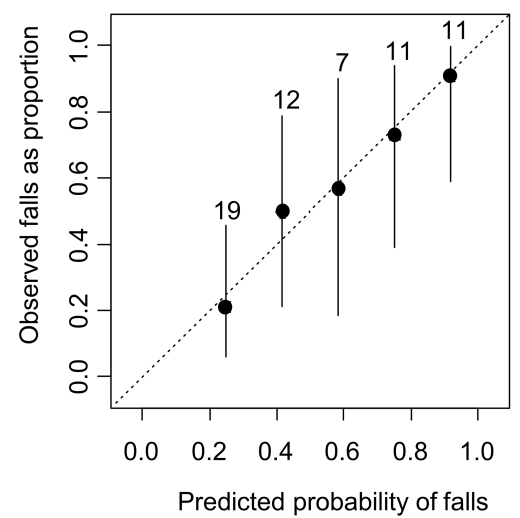

Figure 2 The calibration plots for the A) hip abductor maximum voluntary isometric strength (ABD MVIS), B) hip abductor rate of force generation (ABD RFG), C) the short physical performance battery (SPPB) and D) the timed up and got test (TUG) show good calibration (small discrepancy between predicted probability of falls and observed proportion of falls, all p-values $>0.05)$.

RFG evaluate only one specific dimension of the 3 oftennamed fall-influencing parameters (ie strength, balance, and gait characteristics). ${ }^{34}$ Nevertheless, the influence of the hip abductors on older persons' decreased mediolateral balance control $^{7-9}$ and the femoral-neck-stress-reducing hip abductor muscle contraction at the moment of impact after falling ${ }^{14}$ gives an indication of the importance of this hip muscle group in relation to falls. Therefore, evaluating and understanding the construct of older persons' fall risks might benefit from the additional assessment of hip abductor strength as a not yet systematically assessed parameter to currently used fall risk assessments evaluating complementary aspects of falls.

In Barry et al. ${ }^{2}$ systematic review, including retrospective and prospective studies of community-dwelling persons, the TUG showed an overall AUC of 0.57 (95\% CI, 0.54-0.59) to discriminate between fallers and nonfallers. In another study, the AUC of the TUG to differentiate between persons who fell 6 months prior to hospitalization and persons who did not fall was $0.58 .^{34}$ The AUC for prospectively assessed inhospital and in-hospital injurious falls ranged between 0.64 and $0.67 .{ }^{34}$ The AUC of the TUG in our study was $0.8(95 \%$ CI, 0.7-0.9), which is somewhat higher than the AUC in the aforementioned articles.

In Lauretani et $\mathrm{al}^{3}$ the SPPB showed an AUC of $0.7(95 \%$ CI, 0.6-0.7) to differentiate between persons who fell in the previous 12 months and nonfallers in an outpatient population. ${ }^{3}$ The AUC of the SPPB to identify persons who fell in the 6 months prior to hospitalization was 0.57 , and in the same study, it was between 0.68 and 0.72 for the prospective assessment of in-hospital and in-hospital injurious falls. ${ }^{34}$ For our population, we calculated an AUC of 0.8 (95\% CI, 0.7-0.9), which is again higher than the previously stated values. One explanation for the higher AUC in our study might be the rather heterogeneous study population because we recruited in- and outpatients; it is likely that the 
Table 4 Calculation of net sensitivity for parallel testing of one of the currently used fall risk assessment tools (TUG or SPPB) with the index measure (ABD MVIS or ABD RFG) of our population

\begin{tabular}{|l|l|l|l|l|l|l|l|}
\hline $\begin{array}{l}\text { Current Fall Risk } \\
\text { Assessment Tool }\end{array}$ & $\begin{array}{l}\text { Sens } \\
(\%)\end{array}$ & $\begin{array}{l}\text { Spec } \\
(\%)\end{array}$ & $\begin{array}{l}\text { Index } \\
\text { Measure }\end{array}$ & $\begin{array}{l}\text { Sens } \\
(\%)\end{array}$ & $\begin{array}{l}\text { Spec } \\
(\%)\end{array}$ & $\begin{array}{l}\text { Net Sens For Parallel } \\
\text { Testing (\%) }\end{array}$ & $\begin{array}{l}\text { Net Spec For Parallel } \\
\text { Testing (\%) }\end{array}$ \\
\hline $\begin{array}{l}\text { Sensitivity } \geq 90 \\
\text { TUG }\end{array}$ & 93.8 & 53.6 & ABD MVIS & 90.6 & 57.1 & 99.4 & 30.6 \\
TUG & 93.8 & 53.6 & ABD RFG & 90.6 & 46.4 & 99.4 & 24.9 \\
SPPB & 90.6 & 71.4 & ABD MVIS & 90.6 & 57.1 & 99.1 & 40.8 \\
SPPB & 90.6 & 71.4 & ABD RFG & 90.6 & 46.4 & 99.1 & 33.2 \\
\hline Sensitivity Youden Index & & & & & & & 61.6 \\
TUG & 84.4 & 75.0 & ABD MVIS & 78.1 & 82.1 & 96.6 & 53.6 \\
TUG & 84.4 & 75.0 & ABD RFG & 75.0 & 71.4 & 96.1 & 64.5 \\
SPPB & 87.5 & 78.6 & ABD MVIS & 78.1 & 82.1 & 97.3 & 56.1 \\
SPPB & 87.5 & 78.6 & ABD RFG & 75.0 & 71.4 & 96.9 & \\
\hline
\end{tabular}

Abbreviations: TUG, timed up and go test; SPPB, short physical performance battery; ABD MVIS, hip abductor maximum voluntary isometric strength; ABD RFG, hip abductor rate of force generation.

different patient characteristics (eg results of the functional performance tests and hospitalization rate) could have led to a slight over- or underestimation of the discriminating ability of hip abductor strength. However, to the best of our knowledge, this study is one of the first that has calculated the diagnostic accuracy of hip abductor strength to differentiate between older persons at risk of falls and nonfallers. The inclusion of hospital inpatients and outpatients in a first step allowed the analysis of the variable hip ABD on its full applicability range. Future studies should thus confirm our result using longitudinal designs with a more homogenous sample.

A high sensitivity and specificity is of utmost clinical importance when assessing older persons' fall risks. Regarding the deleterious adverse effects a fall can have for older persons, we chose to determine the diagnostic accuracy by using a high preselected sensitivity of $\geq 90 \%$ instead of the often-used Youden Index. Our chosen approach to calculating the cut-off values implies accepting a small risk of treating too many rather than not enough older persons. For every test used to differentiate between older persons at risk or not at risk of falls, a very wide range of cut-off values is published, indicating that more than one fall risk test is necessary to classify a person into the categories "at risk" or "not at risk." To increase the certainty of detecting as many persons at risk of falls as possible, net sensitivity and specificity calculations should be performed. Parallel testing (performing 2 different tests simultaneously) increases the ability to detect persons at risk of falling (gain in net sensitivity but decrease in net specificity) and allows identification of the most accurate test battery to assess older persons at fall risk. Therefore, we calculated the net sensitivity and specificity when using one of the commonly used fall risk assessment tools (SPPB and TUG) in parallel testing with hip ABD MVIS or ABD RFG in our study population. To make rendering comparisons with other studies easier, we also presented the calculation of the net sensitivity with the sensitivity evaluated by the Youden Index. The calculated net sensitivities in our study (between 96.5 and 99.4) are high and show a good ability of the hip ABD MVIS and RFG combined with the TUG and SPPB to detect persons at risk of falls. On the other hand, the net specificities are lower, indicating that the combination of hip ABD MVIS or RFG with the TUG or SPPB is not useful to detect nonfallers.

Hip abductor strength is easily and reliably assessable. ${ }^{23}$ The inclusion of hospital inpatients and outpatients in this study allowed the analysis of the variable hip ABD on its full applicability range. Our chosen high sensitivity $(\geq 90 \%)$ is a further strength of this study because our choice was to reduce the risk of excluding persons at risk of falls.

A limit of the present study is that the fall history data were not collected in a prospective way, in a rather heterogeneous sample of older participants, which might lead to a slight under- or overestimation of the diagnostic accuracy. It might be that a recall bias influenced the reported number of falls, which might have led to a misclassification. Our strength data are normalized to body mass but we did not take into account the specific weight and length of the participants' leg. This might has influenced the cut-off points of the ABD MVIS and RFG, respectively. 
The above-mentioned results suggest that a proper hip abductor strength assessment can be used as a contribution to a test battery to assess patients' fall risks and indicate a possible weakness.

\section{Conclusion}

Hip abductor strength (MVIS and RFG) shows good diagnostic accuracy to differentiate between older fallers and nonfallers. The high net sensitivity when hip ABD strength measurements (MVIS and RFG) are combined with currently used fall risk assessments shows its promising contributing value to a test battery. Hip abductor strength is an easily measurable parameter and should on a daily clinically basis be considered as an important influencing factor of fall risk. However, further research is needed. Future studies should find pragmatic solutions to reliably and validly assess hip abductor strength in a standard clinical setting and assess the validity of hip abductor strength to predict fall risk in longitudinal studies.

\section{Acknowledgments}

The authors thank all study participants for their participation, as well as all physical therapists who assisted us during this study.

Preliminary results of this article were presented on May 13, 2019, at the World Physiotherapy Congress in Geneva, Switzerland. The study was funded from an internal grant of the HES-SO University of Applied Sciences and Arts of Western Switzerland.

\section{Author Contributions}

All authors contributed to data analysis, drafting or revising the article, gave final approval of the version to be published, and agree to be accountable for all aspects of the work.

\section{Funding}

This study was funded by the HES-SO University of Applied Sciences and Arts of Western Switzerland. The sponsor had no role in the conception, design, methods, subject recruitment, data collection, data analysis and preparation of this article.

\section{Disclosure}

The authors declare no conflicts of interest in this work.

\section{References}

1. WHO World Health Organization report/WHO Global report on falls prevention in older age. 2007. ISBN 9789241563536.

2. Barry E, Galvin R, Keogh C, Horgan F, Fahey T. Is the timed up and go test a useful predictor of risk of falls in community dwelling older adults: a systematic review and meta-analysis. BMC Geriatr. 2014;14:14. doi:10.1186/1471-2318-14-14

3. Lauretani F, Ticinesi A, Gionti L, et al. Short-Physical Performance Battery (SPPB) score is associated with falls in older outpatients. Aging Clin Exp Res. 2018.

4. Hopewell S, Copsey B, Nicolson P, Adedire B, Boniface G, Lamb S. Multifactorial interventions for preventing falls in older people living in the community: a systematic review and meta-analysis of 41 trials and almost 20000 participants. Br J Sports Med. 2019. doi:10.1136/ bjsports-2019-100732

5. Vermeulen J, Neyens JC, van Rossum E, Spreeuwenberg MD, de Witte LP. Predicting ADL disability in community-dwelling elderly people using physical frailty indicators: a systematic review. $B M C$ Geriatr. 2011;11:33. doi:10.1186/1471-2318-11-33

6. Liu SW, Obermeyer Z, Chang Y, Shankar KN. Frequency of ED revisits and death among older adults after a fall. Am J Emerg Med. 2015;33(8):1012-1018. doi:10.1016/j.ajem.2015.04.023

7. Hilliard MJ, Martinez KM, Janssen I, et al. Lateral balance factors predict future falls in community-living older adults. Arch Phys Med Rehabil. 2008;89(9):1708-1713. doi:10.1016/j.apmr.2008.01.023

8. Arvin M, van Dieen JH, Faber GS, Pijnappels M, Hoozemans MJ, Verschueren SM. Hip abductor neuromuscular capacity: a limiting factor in mediolateral balance control in older adults? Clin Biomech. 2016;37:27-33. doi:10.1016/j.clinbiomech.2016.05.015

9. Arvin M, Hoozemans MJ, Burger BJ, et al. Effects of hip abductor muscle fatigue on gait control and hip position sense in healthy older adults. Gait Posture. 2015;42(4):545-549. doi:10.1016/j.gaitpost. 2015.08.011

10. Cofre Lizama LE, Pijnappels M, Faber GH, Reeves PN, Verschueren SM, van Dieen JH. Age effects on mediolateral balance control. PLoS One. 2014;9(10):e110757. doi:10.1371/journal.pone.010757

11. Nankaku M, Kanzaki H, Tsuboyama T, Nakamura T. Evaluation of hip fracture risk in relation to fall direction. Osteopor Int. 2005;16 (11):1315-1320. doi:10.1007/s00198-005-1843-2

12. Hayes WC, Myers ER, Morris JN, Gerhart TN, Yett HS, Lipsitz LA. Impact near the hip dominates fracture risk in elderly nursing home residents who fall. Calcif Tissue Int. 1993;52(3):192-198. doi:10.10 07/BF00298717

13. Greenspan SL, Myers ER, Kiel DP, Parker RA, Hayes WC, Resnick NM. Fall direction, bone mineral density, and function: risk factors for hip fracture in frail nursing home elderly. $\mathrm{Am}$ J Med. 1998;104(6):539-545. doi:10.1016/S0002-9343(98)00115-6

14. Choi WJ, Cripton PA, Robinovitch SN. Effects of hip abductor muscle forces and knee boundary conditions on femoral neck stresses during simulated falls. Osteopor Int. 2015;26(1):291-301. doi:10.1007/s00198-014-2812-4

15. Gafner SC, Bastiaenen CH, Ferrari S, et al. Hip muscle and hand-grip strength to differentiate between older fallers and non-fallers: a cross-sectional validity study. Clin Interv Aging. 2018;13:1-8. doi:10.2147/CIA.S146834

16. Bossuyt PM, Reitsma JB, Bruns DE, et al. STARD 2015: an updated list of essential items for reporting diagnostic accuracy studies. $B M J$. 2015;351:h5527. doi:10.1136/bmj.h6432

17. Fletcher RH, Fletcher SW, Fletcher GS, editors. Clinical epidemiology: the essentials. Fifth edition. Philadelphia: Lippincott Williams \& Wilkins, a Wolters Kluwer business; 2015.

18. Lusardi MM, Fritz S, Middleton A, et al. Determining risk of falls in community dwelling older adults: a systematic review and meta-analysis using posttest probability. $J$ Geriatr Phy Ther. 2017;40(1):1-36. doi:10.1519/JPT.0000000000000099 
19. Yardley L, Beyer N, Hauer K, Kempen G, Piot-Ziegler C, Todd C. Development and initial validation of the Falls Efficacy Scale-International (FES-I). Age Ageing. 2005;34(6):614-619. doi:10.1093/ageing/afi196

20. Folstein MF, Folstein SE, McHugh PR. "Mini-mental state". A practical method for grading the cognitive state of patients for the clinician. J Psychiatr Res. 1975;12(3):189-198. doi:10.1016/0022-3956(75) 90026-6

21. Guralnik JM, Simonsick EM, Ferrucci L, et al. A short physical performance battery assessing lower extremity function: association with self-reported disability and prediction of mortality and nursing home admission. J Gerontol. 1994;49(2):M85-94. doi:10.1093/geronj/49.2. M85

22. Shumway-Cook A, Brauer S, Woollacott M. Predicting the probability for falls in community-dwelling older adults using the Timed up \& go test. Phys Ther. 2000;80(9):896-903. doi:10.1093/ptj/80.9.896

23. Gafner S, Bastiaenen CHG, Terrier P, et al. Evaluation of hip abductor and adductor strength in the elderly: a reliability study. Eur Rev Aging Phy Act. 2017;14:5. doi:10.1186/s11556-017-0174-6

24. Krause DA, Schlagel SJ, Stember BM, Zoetewey JE, Hollman JH. Influence of lever arm and stabilization on measures of hip abduction and adduction torque obtained by hand-held dynamometry. Arch Phys Med Rehabil. 2007;88(1):37-42. doi:10.1016/j.apmr.2006.09.011

25. Morcelli MH, Rossi DM, Karuka AH, et al. Peak torque, reaction time, and rate of torque development of hip abductors and adductors of older women. Phys Theory Pract. 2016;32(1):45-52. doi:10.3109/ 09593985.2015.1091870

26. Allet L, Kim H, Ashton-Miller J, De Mott T, Richardson JK. Frontal plane hip and ankle sensorimotor function, not age, predicts unipedal stance time. Muscle Nerve. 2012;45(4):578-585. doi:10.1002/mus.22325
27. Pamoukdjian F, Paillaud E, Zelek L, et al. Measurement of gait speed in older adults to identify complications associated with frailty: a systematic review. $J$ Geriatr Oncol. 2015;6(6):484-496. doi:10.1016/j.jgo.2015.08.006

28. Podsiadlo D, Richardson S. The timed "up \& go": a test of basic functional mobility for frail elderly persons. $J$ Am Geriatr Soc. 1991;39(2):142-148. doi:10.1111/j.1532-5415.1991.tb01616.x

29. Palmer TB, Thiele RM, Williams KB, et al. The identification of fall history using maximal and rapid isometric torque characteristics of the hip extensors in healthy, recreationally active elderly females: a preliminary investigation. Aging Clin Exp Res. 2015;27 (4):431-438. doi:10.1007/s40520-014-0305-0

30. Bujang MA, Adnan TH. Requirements for minimum sample size for sensitivity and specificity analysis. JCDR. 2016;10(10):Ye01-ye06. doi:10.7860/JCDR/2016/18129.8744

31. Hosmer DW, Lemeshow S. Applied Logistic Regression. New York: Wiley; 2013.

32. Bento PC, Pereira G, Ugrinowitsch C, Rodacki AL. Peak torque and rate of torque development in elderly with and without fall history. Clin Biomech. 2010;25(5):450-454. doi:10.1016/j.clinbiomech.2010.02.002

33. Ward RE, Leveille SG, Beauchamp MK, et al. Functional performance as a predictor of injurious falls in older adults. $\mathrm{J}$ Am Geriatr Soc. 2015;63(2):315-320. doi:10.1111/jgs.13203

34. Hars M, Audet MC, Herrmann F, et al. Functional performances on admission predict in-hospital falls, injurious falls and fractures in older patients: a prospective study. J Bone Min Res. 2018;33:852-859. doi:10.1002/jbmr.3382
Clinical Interventions in Aging

\section{Publish your work in this journal}

Clinical Interventions in Aging is an international, peer-reviewed journal focusing on evidence-based reports on the value or lack thereof of treatments intended to prevent or delay the onset of maladaptive correlates of aging in human beings. This journal is indexed on PubMed Central, MedLine, CAS, Scopus and the Elsevier

\section{Dovepress}

Bibliographic databases. The manuscript management system is completely online and includes a very quick and fair peer-review system, which is all easy to use. Visit http://www.dovepress.com/ testimonials.php to read real quotes from published authors. 